\title{
An overview of natural plant antioxidants: analysis and evaluation
}

\author{
Mohammed Sulaiman 1, ", Hamzat Ibiyeye Tijani ${ }^{2}$, Bashir Mohammed Abubakar ${ }^{3}$, \\ Saidu Haruna ${ }^{4}$, Yusuf Hindatu ${ }^{5}$, Jibrin Ndejiko Mohammed ${ }^{6}$, Abdulrahman Idris ${ }^{7}$ \\ ${ }^{1}$ Department of Biological Sciences, Gombe State University, PMB 0127, Gombe, Nigeria \\ ${ }^{2}$ Faculty of Bioscience \& Medical Engineering, Universiti Teknologi Malaysia, 81310 Skudai, Johor-bahru, Malaysia \\ ${ }^{3}$ Department of Biological Sciences, Bauchi State University Gadau, P.M.B 065, Bauchi, Nigeria \\ ${ }^{4}$ Department of Biological Sciences, Gombe State University, PMB 0127, Gombe, Nigeria \\ ${ }^{5}$ Department of Biochemistry, Bauchi State University Gadau, P.M.B 065, Bauchi, Nigeria \\ ${ }^{6}$ Department of Microbiology, Ibrahim Badamasi Babangida University Lapai, P.M.B 011, Niger, Nigeria \\ ${ }^{7}$ Department of Microbiology, Kaduna State University, P.M.B. 2339, Kaduna, Nigeria
}

\section{Email address:}

sumulsu@yahoo.com (M. Sulaiman),janyzrux@gmail.com (H. I. Tijani), elbash1150@yahoo.com (B. M. Abubakar), saiduharunn@yahoo.com (S. Haruna),yusufhindat@yahoo.com (Y. Hindatu),ndejiko@gmail.com (J. N. Mohammed), abdurrahman.idris@kasu.edu.ng (A. Idris)

\section{To cite this article:}

Mohammed Sulaiman, Hamzat Ibiyeye Tijani, Bashir Mohammed Abubakar, Saidu Haruna, Yusuf Hindatu, Jibrin Ndejiko Mohammed, Abdulrahman Idris. An Overview of Natural Plant Antioxidants: Analysis and Evaluation. Advances in Biochemistry.

Vol. 1, No. 4, 2013, pp. 64-72. doi: 10.11648/j.ab.20130104.12

\begin{abstract}
Antioxidative compounds play a vital role to inhibit the oxidation of oxidizable products and influences the body defense system against Reactive Oxygen Species (ROS), which are harmful byproducts engendered during normal aerobic cellular respiration. ROS are specialized class of highly reactive molecules that originates during oxygen metabolism, whereas extensive evidences indicate the involvement of ROS in the development of degenerative diseases in humans. Despite the fact that synthetic antioxidants such as butylated hydroxyanisole (BHA) and butylated hydroxytoluene (BHT) are threat to human's health; they are widely employed as chemical preservatives to avert potential deterioration of food products. Several toxicological findings reveal that natural antioxidants are capable of providing protection against free radical-related diseases, cancer and other cardiovascular infections. In cognizance with these facts, natural antioxidant attracts a great deal of research interest; therefore, this review provides a comprehensive and an up-to-date overview of the three most essential natural plant antioxidants; their antioxidative properties, methods of analysis and evaluation. These Polyphenols comprise: Phenolic acid, an essential polyphenol that are broadly dispersed in plants to exert positive influence on oxidative stress; Flavonoid, an ubiquitous antioxidant that functions in free radical scavenging, metal ion chelation and enzymes inhibition to suppress the synthesis of free radicals; and Tannic acid, a water soluble anti-nutrient that acts to precipitate alkaloids $\&$ proteins, reduce mineral \& vitamin utilization and restrict the activities of digestive enzymes. In conclusion, a variety of plant species were characterized to indicate in vitro antioxidative properties.
\end{abstract}

Keywords: Antioxidant, Analysis, ROS, Polyphenols, Phenolic Acid, Flavonoid, Tannic Acid

\section{Introduction}

There is now upsurge interest in antioxidant activity of phytochemicals present in the diet [1]. Antioxidants are compounds that can prevent or delay the oxidation of oxidizable products by scavenging free radicals and reducing oxidative stress. Oxidative stress is an imbalanced state where excessive quantities of reactive oxygen and/or nitrogen species overshadow the endogenous antioxidative capability of the cells which stimulates the oxidation of macromolecules, such as proteins, enzymes, lipids and DNA [2].

Oxidative stress signifies the presence of ROS and free radicals. The complex synthesis of these free radical from oxygen i.e. ROS induce significant damage to the intermediate metabolite via electron loss in order to remain stable. These free radicals possess a single or more unpaired electrons spinning on the peripheral layer around the nucleus. 
These are oxygen-centered free radicals consisting of superoxide anion $\left(\mathrm{O}_{2}\right)$, alkoxyl $\left(\mathrm{RO}^{-}\right)$, peroxyl $\left(\mathrm{ROO}^{-}\right)$, hydroxyl radical $\left(\mathrm{OH}^{-}\right)$and nitric oxide. They are formed under typical physiological conditions and then become detrimental if not being eliminated by the endogenous metabolizing systems $[3,4]$. ROS are not only associated with lipid peroxidation that causes the food deterioration, but also entangled in the development of human diseases such as cellular aging, carcinogenesis, coronary heart disease, diabetes, mutagenesis and neurodegenerative infections.

Antioxidant compounds play a vital role to the body defense system against Reactive Oxygen Species (ROS), which are the harmful byproducts engendered during normal aerobic cellular respiration [1]. [5] reports that the influence of antioxidants are predominantly determined by their ability to establish anti-aging effects and free radical damage. The functional role of antioxidant is to prevent oxidation of highly reactive free radicals which is a chemical process that are known to cause premature aging, cancer and other cardiovascular infections [4]. Antioxidants from natural source increase the antioxidative capability of the plasma and decrease the risk of many diseases. The increase in dietary antioxidant intakes may help to support the limiting antioxidant concentrate and also promote the normal functioning of physiological systems [1].

While unknown to many, the synthetic antioxidants; butylated hydroxyanisole (BHA) and butylated hydroxytoluene (BHT) are most extensively used as alternative preservatives to prevent unwanted deterioration of food products, which poses threat to human's health [6]; thus, there is necessity for less toxic, cost effective and more efficient antioxidants [4].

The fact that a variety of natural antioxidants occur in plants has been proven [6]; these comprise of phenolic acid, flavonoids/bioflavonoid, tannic acid (tannins) and commonly less lignans and stilbenes which are collectively referred to as polyphenols (phenolics). They are predominantly found in medicinal plant parts such as fruits, leaves and vegetables plants (see Table 1) $[1,7]$. Therefore, the overall goal of this review is to provide an insight into the antioxidative analysis of products from a natural sources and evaluating their properties based on the scientific perspective, most of them encompassing polyphenols and already considered to be valuable phytomedicines.

\section{Phenolics and their Antioxidative Properties}

Phenolics are organic acids composed of one or more hydroxyl groups linked to a single or multiple aromatic rings. The versatility of phenolics in the organs of different plant species necessitated it as functional secondary metabolites for human biological systems. It is a predominant constituent of plant nutrients found in vegetables \& fruits and primarily accounts for the organoleptic properties of phyto-foods [2]. It has also been reported that these acidic compounds found in plant sources exists at varying concentrates.

Recently, phenolics antioxidative properties have been considered active in vitro and confirmed to be more reactive than carotenoids, Vitamin C and E [9]. The metabolic activities of fruit and vegetable intakes in preventing the risk of oxidative stress and other associated syndromes such as cancer and cardiovascular diseases has been partially ascribed to phenolics $[10,11]$. The antioxidative properties of phenolic compounds have been analysed and achieved via three main mechanisms:

I. Scavenging radical species (for removing impurities) such as reactive oxygen species (ROS) and reactive nitrogen species (RNS).

II. Suppression of ROS/RNS synthesis by inhibiting specific enzymes or chelating trace metals involved in free radical generation.

III. Up-controlling or inhibition of antioxidant defense system [2].

\subsection{Phenolics Sample Preparation and Characterization}

\subsubsection{Extraction}

The bioactive compounds are first extracted from plant materials for the analysis of phytochemicals to standardize the preparation technique of dietary supplements, pharmaceutical \& cosmetic products and food ingredients. Extraction of polyphenols can be from fresh/dried/frozen samples [2]. Grinding, milling and homogenization treatment are mostly carried out on the samples before the extraction process (see Figure 1) and may be preceded by freeze drying or air drying $[2,6]$.

\subsubsection{Purification and Fractionation}

Extracts from plant crude materials usually contain high quantity of carbohydrate and lipid components, which influences the phenolics concentration in the crude extract. The precipitation and determination of polyphenols-rich fractions prior to analysis include solid phase extraction (SPE) based on acidity \& polarity and/or column chromatography (see Figure 1) [2].

\subsubsection{Analysis}

Polyphenol assays are usually grouped either in the quantification or classification of specific phenolic compounds. The quantification of phenolics in plant extract is controlled by the chemical nature of the analyte $\&$ assay procedure, standards selection and presence of interfering constituents. Because of the heterogenic natural of phenolics and its limitation to other readily oxidizable substances in plant materials, several methods for the determination of total polyphenols have been established. These include Folin-Ciocalteu (F-C) method, Folin-Denis (F-D) method [2], colorimetry (using iron salts), ultraviolet absorbance and permanganate titration as shown in Figure 1. Mostly, the F-C method is more preferred to other quantification methods due to its accuracy [2, 12, 13, 14]. 


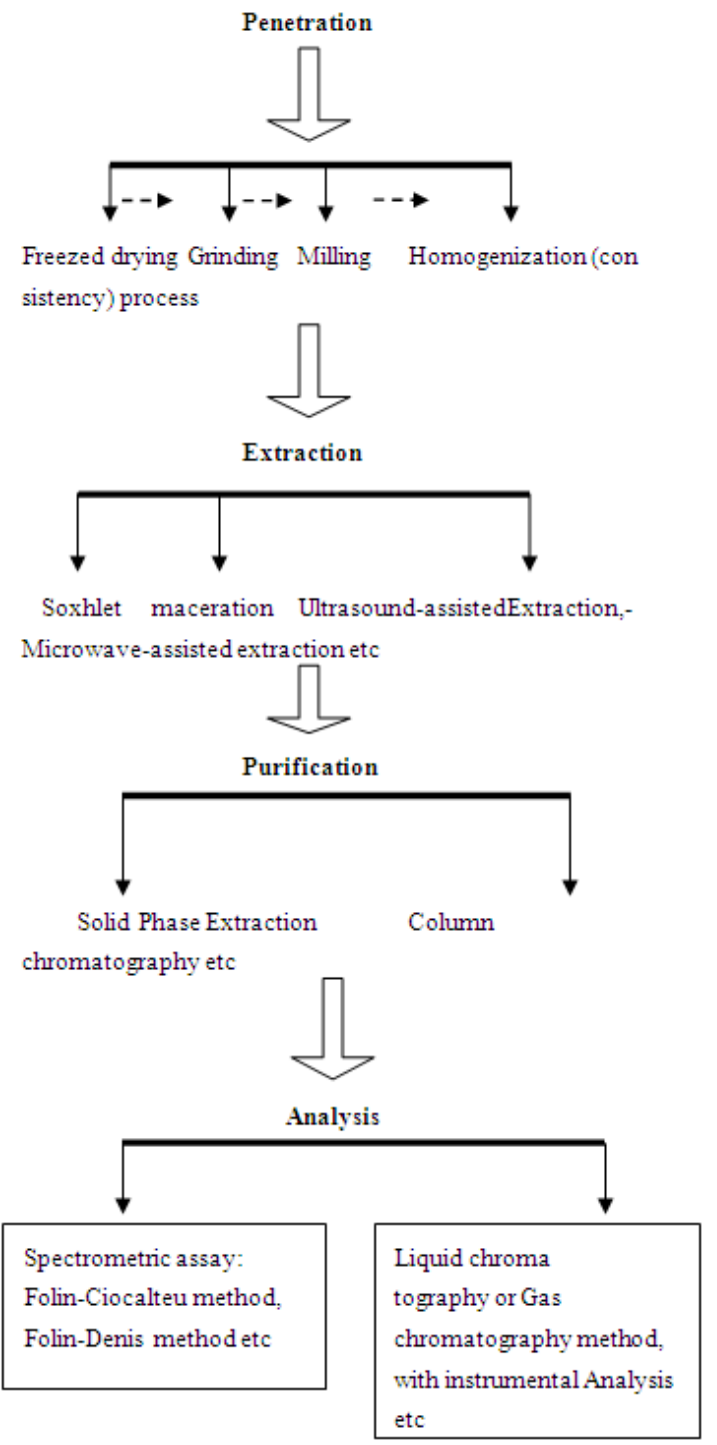

Figure 1; Preparation strategies and characterization of plant phenolics samples $[2,8]$.

\section{Polyphenols Antioxidant Analysis}

For chemical analysis of polyphenols, appropriate dilution of sample powder of plant organ is usually measured and used as aliquot. Phenolics compound are extracted from $0.5 \mathrm{~g}$ plant sample with $40 \mathrm{~mL}$ of $80 \% \mathrm{v} / \mathrm{v}$ acetone or aqueous methanol under sonication bath for 20 minutes. The residual solution is subsequently centrifuged at $4000 \mathrm{rpm}$ for $10 \mathrm{~min}$ and collects the supernatant for the analysis $[6,13,15]$.

\subsection{Phenolic acid}

Phenolic acids belong to a group of natural products which originate from several cereals and fruits. Higher concentrations of this compound are found at the superficial layers of the kernel which set-up the bran [16]. As a group, phenolic acid have been found as strong antioxidants against the negative influence of free radicals and ROS, which is the basis of several chronic human diseases [17, 18].
Phenolic acid is categorized into 2-classes

I. Derivatives of cinnamic acid (caffeic acid and ferulic acid).

II. Derivatives of benzoic acid (gallic acid) [19].

The most common phenolic acid in fruits \& vegetables is caffeic acid which is esterified with quinic acid. While ferulic acid is abundant in cereals and esterified to hemicelluloses, an essential component of the cell wall [2, 20]. The structural diversity of the different phenolic acids are based on their variation in hydroxylation pattern and stereochemistry which are determined by various analysis and characterization as illustrated in Figure 2,.



Hydroxybenzoic acid<smiles>CC(C)(C)c1cc(C(=O)O)cc(O)c1O</smiles>

Figure 2; Structure onfiguration of the different phenolic acids [2].

\subsection{Determination of Total Phenolic Acid Content}

Total amount of phenolic can be determined by Folin-Ciocateu assay as proposed by $[21,22] .0 .2-0.5 \mathrm{~mL}$ of aliquot extract is mixed with $0.1 \mathrm{ml}$ of Folin-Ciocalteu reagent (mixture of molybdenum oxides and tungsten) in a volumetric flask containing deionized distilled water and incubates at room temperature. $5-10 \mathrm{~mL}$ of sodium carbonate $\left(\mathrm{Na}_{2} \mathrm{CO}_{3}\right)$ is added to the mixture and the solution is diluted with distilled water, prior to incubation at room temperature for an hour or more. The absorbance is read at wavelength of $765 \mathrm{~nm}$ using UV-VIS spectrophotometer with blank [4, 8, 13]. Gallic acid solution is prepared as standard at $100 \mathrm{mg} / \mathrm{L}[6,23]$ and total phenolic content is expressed as a standard equivalent of the extracted compound [4].

\subsection{Flavonoids}

Flavonoids are polyphenolic compounds that are ubiquitous in nature, comprising a number of hydroxyl groups attached to aromatic ring structures which determines its antioxidant activity. The compounds exhibit a diphenylpropane $\left(\mathrm{C}_{6}-\mathrm{C}_{3}-\mathrm{C}_{6}\right)$ skeleton and classified according to their chemical structure as:
a- Monomeric flavanols
b- Flavonols
c- Flavones 


\section{d- Flavanones and}

e- Anthocyanidins (anthocyanin) (refer to Figure 3)

In addition to hydroxycinnamic acid derivatives (C6-C3), phenylpropanoids, flavonols and flavones exist in lesser quantity in many plant species. Flavones and flavanones are mostly found in citrus fruits; flavonol is abundant in apple, tea and onion; while anthocyanin are responsible for the red colouration of several fruits (e.g. strawberry, raspberry etc.) which are all attached by peculiar enzymes. The flavonoid metabolic interconnections are illustrated in Figure 4. Individual variations within these groups are as a result of the differences in the nature \& structural organization of its hydroxyl groups, degree of glycosylation and/or alkylation.

Flavonoids are of beneficial advantages to humans due to its capacity to function as antioxidant, anti-allergic, anti-viral, anti-inflammatory, anti-carcinogenic, anti-bacterial, anti-tumor, immune-stimulating, vasodilatory and estrogenic drives. $[2,9,11,24]$. The antioxidant potency of flavonoids has been evaluated in vitro by measuring their ability to trap free radicals and demote more chemicals. This ability depends upon the molecular structure of the compounds [10, 25]. Flavonoids' antioxidative capacity influences different metabolic mechanisms that includes free radical scavenging, metal ions chelation and enzymes inhibition responsible for free radical generation [4, 24]. As earlier reported, the chemical structure and hydroxyl group positioning in polyphenols are important features of flavonoids as scavengers of free radical/superoxide while exerting antioxidant activities, inhibitory effects on lipid peroxidation, inhibition of low density lipoproteins (LDL) oxidation induced by copper ions and macrophages [24].

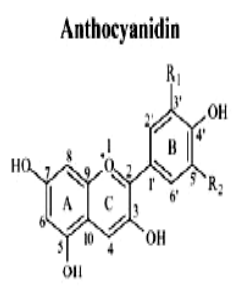

Delphinidin: $R_{1}=R_{2}=O H$ Cyanidin: $\mathrm{R}_{1}=\mathrm{OH}, \mathrm{R}_{2}=\mathrm{H}$

Flavone<smiles>[R]c1ccc(-c2cc(=O)c3c([2H])c([R])c([2H])cc3o2)cc1[R]</smiles>

Apigenin: $R_{1}=R_{3}=R_{4}=O H_{1} R_{2}=R_{3}=H$ Luteonin: $R_{1}=R_{3}=R_{4}=R_{9}=O H, R_{7}=H$

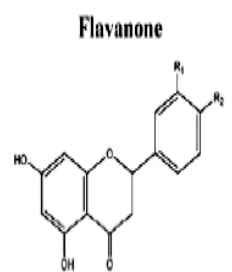

Hesperetin: $\mathrm{R}_{1}=\mathrm{OH}, \mathrm{R}_{1}=\mathrm{OCH}$ Naringenin: $\mathrm{R}_{1}=\mathrm{H}, \mathrm{R}_{3}=\mathrm{OH}$

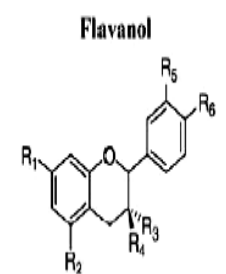

Catechin: $R_{1}=R_{2}=R_{1}=R_{3}=R_{6}=O H, R_{1}=H$ $\mathrm{R}_{1}=\mathrm{H}$ Epicalechin: $R_{1}=R_{3}=R_{3}=R_{5}=R_{6}=0 H_{\text {, }}$

Figure 3; Chemical structure of the different sub-classes of flavonoid based on variations in heterocyclic C-ring [2, 11].
The pharmacological, medicinal and biological characterization of flavonoids has been extensively reviewed. The antioxidant properties is hypothesized to protect tissues against ROS and lipid peroxidation which are linked to many many pathological states such as atherosclerosis and chronc inflammation. Thus, flavonoids contribute immensely towards deterrence of such diseases. They also act as inhibitors of cyclooxygenase, phospholipase A2 \& lipoxygenase, xanthine oxidase and glutathione reductase.

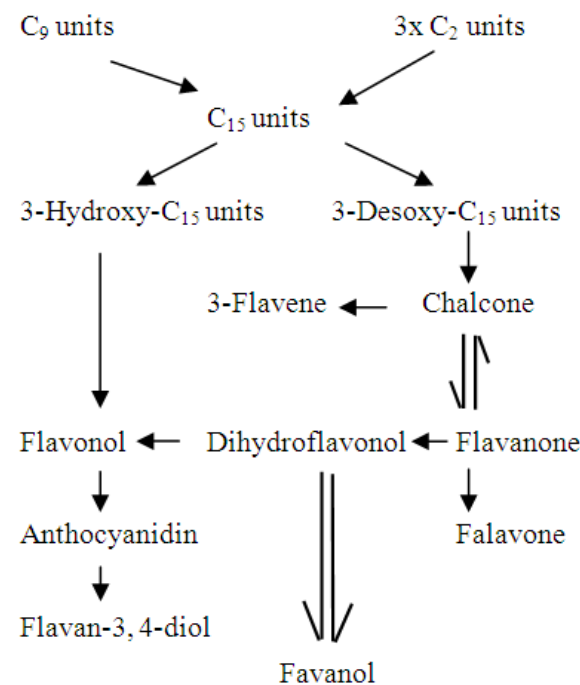

Figure 4; Metabolic chains for the synthesis of different sub-classes of flavonoids

\subsection{Determination of Total Flavonoid Content}

The total amount of flavonoid can be determined by modified colorimetric assay [4] or aluminium chloride colorimetric method [13,26]. 0.1-0.5 mL of an aliquot extract is mixed with $2-4 \mathrm{~mL}$ of distilled water in volumetric flask. Subsequently, 0.1-0.3 $\mathrm{mL}$ of $\mathrm{NaNO}_{2}$ is added and well mixed. After 5 min of incubation, $0.15-0.3 \mathrm{~mL}$ of $\mathrm{AlCl}_{3}$ solution should be added and preceded for $5 \mathrm{~min}$ incubation at room temperature and $2 \mathrm{~mL}$ of $1 \mathrm{M} \mathrm{NaOH}$ solution is added to the test solution. This is followed by mixing and incubation for 20minutes at room temperature. Absorbance is read to quantify the total flavonoid content by using UV-visible spectrophotometer/HACH spectrophotometer programme, DR 5000 at $510 \mathrm{~nm}$ versus prepared blank with distilled water. Rutin (E. Merck) as standard compound or quercetin is used for calibration curve $[4,6,13]$.

\subsection{Tannic Acid (Tannins)}

Tannic acid is a water-soluble polyphenol with molecular weight of 500-3000 g/mol. Apart from its phenolic reactions; tannins possess specific properties that cannot be found in other natural antioxidants. These include the ability to precipitate alkaloids and other proteins. They are responsible for the bitter taste of certain beverages and foods such as tea, wine and unripe fruits. This sensation apparently results from the molecular interaction between tannic acid 
constituents and salivary proteins secreted from the mouth mucous tissue $[27,28]$. As a result, tannins are defined as anti-nutrients' from plant origin that can precipitate proteins, reduce mineral ions \& vitamins utilization and prevent the activities of digestive enzymes. Likewise, tannins are considered as health-promoting components in plants and beverages [27]. For instance, it possesses anti-mutagenic and anti-carcinogenic potentials in addition to its anti-microbial properties as reported by [29].

Moreover, the consumption of this polyphenol has been in line to establish preventive and inhibitory effects in human heart related diseases. In addition, tannins inhibit lung, skin and fore-stomach tumor infections which are primarily caused by the degenerative activity of $\mathrm{N}$-methyl-N-nitrosourea and polycyclic aromatic hydrocarbon carcinogens [30].

The phenolic nature of tannins which is embedded within its comparatively hydrophilic "shell" and hydrophobic "core" are the features responsible for its antioxidant action $[30,31]$. The properties of tannin-rich extracts was observed in meat model system studies on bearberry leaf (Arctostaphylos uva-ursi) extract and characterized by the existence of hydrolysable and condensed tannins [32]. Tannins act as secondary antioxidants and does not function independently as primary antioxidants (i.e. it donates electrons or hydrogen atom). This compound possesses the power to chelate metal ions such as $\mathrm{Fe}^{2+}$ and interferes with metabolic phase of Fenton reaction to retard oxidation [33].

Structurally, tannins are made up of a central glucose molecule and 10 galloyl groups. The molecular derivatives of tannic acid with one or more galloyl residues at its hydroxyl positions are illustarted in figure 5 . This represents the form of polyphenols present in fruits and plant barks (e.g. grapes, bananas, sorghum, coffee, red wine, persimmons and tea) [34].

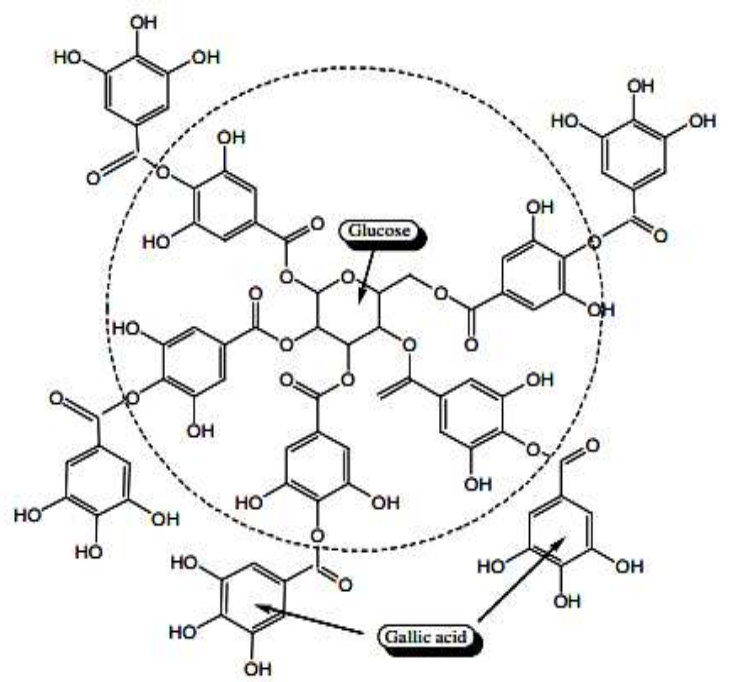

Figure 5. Chemical structure of tannic acid, deca-galloyl glucose containing the central glucose molecule and two gallic acid molecules. The shaded circle highlights the core structure of tannic acid and pentagalloyl glucose [30].

\subsection{Determination of Tannic Acid}

Tannic acid content in vegetables and fruits are analyzed according to AOAC and Pharmacopoeia methods. $25 \mathrm{~mL}$ of infusion is provided in $1 \mathrm{~L}$ conical flask containing $2 \mathrm{~mL}$ of indigo solution and $750 \mathrm{~mL}$ of deionised distilled water. Aqueous solution of $\mathrm{KMnO}_{4}$ is used in burette titration until the blue coloration of the mixture turns green. Chemical indicator is continuously dropped until the solution becomes golden yellow. However, a standard solution of Indigo camine is prepared by dissolving $6 \mathrm{~g}$ of Indigo camine into $50 \mathrm{~mL}$ deionized distilled water while heating and allowed to cool before $50 \mathrm{~mL}$ of $95-97 \% \mathrm{v} / \mathrm{v} \mathrm{H}_{2} \mathrm{SO}_{4}$ is added to dilute the solution to $1 \mathrm{~L}$ prior to filtration [35].

\subsection{Total Condensed Tannic Acid determination}

For total condensed tannins determination in gambir extract samples. $100 \mathrm{mg}$ of sample is dissolved in $10 \mathrm{~mL}$ of distilled water and $2 \mathrm{~mL}$ of $37 \% \mathrm{v} / \mathrm{v}$ formaldehyde (Merck) is added. Thereafter, $2 \mathrm{~mL}$ of $5 \mathrm{M} \mathrm{HCl}$ are added and the mixture is heated under reflux for an hour before filtration is established via vacuum suction while it is still hot. The reddish precipitate observed is washed 5 times with 10 $\mathrm{mL}$ warm water and dried using silica gel desiccators and total condensed tannic acid is measured [36].

\subsection{Antioxidant Activity Evaluation}

Several analytical procedures have been employed to determine the effectiveness of natural antioxidants, as either pure compounds or extract from plant. In vitro techniques are classified into two main classes:

I. Hydrogen atom transfer reactions; includes Total Radical Trapping Antioxidant potential (TRAP), $\beta$ carotene bleaching and Oxygen Radical Absorbance Capacity (ORAC).

II.Electron transfer reactions; includes Ferric Reducing Antioxidant Power (FRAP), Trolox Equivalent Antioxidant Capacity (TEAC), Superoxide anion radical scavenging assay, Hydroxyl radical scavenging assay etc [37].

The above system techniques are the most popular due to their sensitivity and accuracy. Though, it is important to use more than a single method to evaluate plant material antioxidant power, because of the complex nature of phytochemicals. Antioxidants evaluation assay commonly used with variety of standards as positive control.

Extraction of Antioxidant for Evaluation; The plant material is subjected to extractions with water and acetone. For acetone extraction, approximately $10 \mathrm{~g}$ of the plant material is powdered using ordinary blender or laboratory mill. $0.5 \mathrm{~g}$ of the powdered is taking to extraction tubes and mixed with $20 \mathrm{~mL}$ of the extragent (i.e. $80 \%$ acetone in $0.2 \%$ formic acid). This extraction is conducted on an orbital shaker at room temperature for an hour. After then, the sample is centrifuged and collects the supernatant and re-extracts the solids residue under the same conditions. Both the supernatants from first and second extraction are 
combined and evaluate for antioxidant activity [38].

For water extraction; water infusions is prepared in compliance with the traditional preparation which is close to home conditions. $5 \mathrm{~g}$ of powdered material is added to 200 $\mathrm{mL}$ of $90{ }^{0} \mathrm{C}$ water and collects the supernatant after centrifugation [38]. These are the extraction procedures, while the next is evaluation analysis. In this review single evaluation method was reviewed that is ORAC assay.

ORAC assay: ORAC is measured according to the method of $[39,40]$. This method measures the antioxidant scavenging activity against of peroxyl radical generated by thermal decomposition of AAPH at $37{ }^{\circ} \mathrm{C}$. Fluorescein (FL) is used as the fluorescent probe. The loss of fluorescence of FL is an indication of the extent of damage from its reaction with the peroxyl radical. The antioxidant protective effect is measured by evaluating the fluorescence decay curve (AUC) relative to that of a blank without the presence of antioxidant. AAPH solution, Trolox and fluorescein are prepared with phosphate buffer (75 mmol/1, pH 7.4) as dilution liquid [38].

Reaction mixture (about $200 \mu \mathrm{L}$ ) contained $170 \mu \mathrm{L}$ of FL, $20 \mu \mathrm{L}$ of AAPH, and $10 \mu \mathrm{L}$ of sample. The sample and FL are incubated at $37{ }^{\circ} \mathrm{C}$ for $10-30 \mathrm{~min}$ in a microplate reader with AAPH that dissolved in buffer at $37{ }^{\circ} \mathrm{C}$ is added and read the initial fluorescence after incubation for $30 \mathrm{sec}$. The readings are taken after 1 min shaking cycle. Blank is prepared with $10 \mu$ of phosphate buffer. The antioxidant activity is expressed in micromole Trolox equivalents per gram of dry weight. Trolox solutions in different $\mu \mathrm{mol} / \mathrm{L}$ are used for defining the standard curve [38].

Table 1.0:- List of some plant species with their family and part(s) examined for antioxidant compounds studies

\begin{tabular}{|c|c|c|c|}
\hline Plant species & Family & Part examined & Reference \\
\hline Solanum lycopersicum & Solanaceae & friut & {$[41,42]$} \\
\hline Mangifera indica L & Anacardiaceae & Fruit & {$[43]$} \\
\hline Moringa oleifera & Moringaceae & fruit and leaves & [44] \\
\hline Piper nigrum Linn & Piperaceae & Fruit and seed & {$[45]$} \\
\hline Azadirachta indica & Meliaceae & Leaves & {$[46]$} \\
\hline Amaranthus lividus L & Amaranthaceae & leaves flower and stem & {$[47]$} \\
\hline Allanblackia floribunda Oliv & Guttiferae & leaves and fruits & {$[48]$} \\
\hline Aristotelia chilensis & Elaeocarpaceae & fruit & {$[49]$} \\
\hline Careya arborea Roxb & Barringtoniaceae & bark & {$[50]$} \\
\hline Cassia siamea Lam & Caesalpiniaceae & flower & {$[51,52]$} \\
\hline Citrullus colocynthis L & Cucurbitaceae & fruit & {$[53]$} \\
\hline Cydonia vulgaris & Rosaceae & Leaves, fruit & {$[54,55]$} \\
\hline Dimocarpus Longan Lour & Sapindaceae & leaves & {$[56,57]$} \\
\hline Dipsacus asper Wall & Dipsacaceae & root & {$[58]$} \\
\hline Cassia tora $\mathrm{L}$ & Caesalpiniaceae & seeds & {$[59]$} \\
\hline Pyrrosia petiolosa Ching & Polypodiaceae & whole plant & {$[5]$} \\
\hline Phyllanthus emblica L & Euphorbiaceae & fruit & {$[60,61]$} \\
\hline Lecaniodiscus cupanioides Planch & Sapindaceae & leaves & {$[5]$} \\
\hline Phoenix dactylifera L & Arecacea & fruit & {$[62,63]$} \\
\hline Phyllanthus niruri Linn & Euphorbiaceae & fruit and leaves & {$[64]$} \\
\hline Uncaria tomentosa Willd.DC & Rubiaceae & back & {$[65]$} \\
\hline Trigonella foenum-graecum L & Leguminosae & seed & {$[66]$} \\
\hline Curcuma longa & Zingiberaceae & Rhizome & {$[67]$} \\
\hline Cynamonum zeylanicum & Lauraceae & seed & {$[66]$} \\
\hline Carum carvi & Umbelliferae & fruit & {$[66,68]$} \\
\hline Phytolacca Americana & Phytolaccaceae & leaves & {$[69]$} \\
\hline Capparis spinosa & Capparaceae & leaves & {$[70]$} \\
\hline Syzygium aromaticum & Myrtaceae & fruit & {$[66,71]$} \\
\hline
\end{tabular}




\section{Conclusion}

Concisely, plant polyphenols have been found to play a vital role in human biological systems and influence major stages of disease development in addition to their antioxidative power. Solvents such as methanol are mostly used for the extraction of antioxidants (bioactive compounds) from it source according to the variations in the polarity of the solvent prior to water extraction techniques. The usage of non-polar solvents is relatively rare due to the characteristics of the active constituents with higher solubility in polar solvents. Usually, all plant parts can be used for antioxidant analysis and evaluation, but fruits/seeds and leaves are mostly been analyzed. This review achieves the aim of providing useful information on polyphenol analysis, its properties and evaluation. However, extensive studies of these natural plant antioxidants will provide significant insights to their potential pharmaceutical functions in the field of oncology.

\section{References}

[1] Ou, B., et al., Analysis of antioxidant activities of common vegetables employing oxygen radical absorbance capacity (ORAC) and ferric reducing antioxidant power (FRAP) assays: a comparative study. Journal of Agricultural and Food Chemistry, 2002. 50(11): p. 3122-3128.

[2] Dai, J. and R.J. Mumper, Plant phenolics: extraction, analysis and their antioxidant and anticancer properties. Molecules, 2010. 15(10): p. 7313-7352.

[3] Chanda, S. and R. Dave, In vitro models for antioxidant activity evaluation and some medicinal plants possessing antioxidant properties: An overview. African Journal of Microbiology Research, 2009. 3(13): p. 981-996.

[4] Zou, Y., Y. Lu, and D. Wei, Antioxidant activity of a flavonoid-rich extract of Hypericum perforatum L. in vitro. Journal of Agricultural and Food Chemistry, 2004. 52(16): p. 5032-5039.

[5] Kaur, C. and H.C. Kapoor, Antioxidants in fruits and vegetables-the millennium's health. International Journal of Food Science \& Technology, 2001. 36(7): p. 703-725.

[6] Siddhuraju, P. and K. Becker, Antioxidant properties of various solvent extracts of total phenolic constituents from three different agroclimatic origins of drumstick tree (Moringa oleifera Lam.) leaves. Journal of Agricultural and Food Chemistry, 2003. 51(8): p. 2144-2155.

[7] Pietta, P., P. Simonetti, and P. Mauri, Antioxidant activity of selected medicinal plants. Journal of Agricultural and Food Chemistry, 1998. 46(11): p. 4487-4490.

[8] Waterhouse, A.L., Wine phenolics. Annals of the New York Academy of Sciences, 2002. 957(1): p. 21-36.

[9] Rice-evans, C.A., et al., The relative antioxidant activities of plant-derived polyphenolic flavonoids. Free radical research, 1995. 22(4): p. 375-383.
[10] Scalbert, A., et al., Dietary polyphenols and the prevention of diseases. Critical reviews in food science and nutrition, 2005. 45(4): p. 287-306.

[11] Hollman, P.C.H. and M. Katan, Dietary flavonoids: intake, health effects and bioavailability. Food and Chemical Toxicology, 1999. 37(9): p. 937-942.

[12] Atanassova, D., P. Kefalas, and E. Psillakis, Measuring the antioxidant activity of olive oil mill wastewater using chemiluminescence. Environment international, 2005. 31(2): p. 275-280.

[13] Atanassova, M., S. Georgieva, and K. Ivancheva, Total phenolic and total flavonoid contents, antioxidant capacity and biological contaminants in medicinal herbs. Journal of the University of Chemical Technology and Metallurgy, 2011. 46(1): p. 81-88.

[14] Dudonne, S., et al., Comparative study of antioxidant properties and total phenolic content of 30 plant extracts of industrial interest using DPPH, ABTS, FRAP, SOD, and ORAC assays. Journal of Agricultural and Food Chemistry, 2009. 57(5): p. 1768-1774.

[15] Proestos, C., et al., Analysis of flavonoids and phenolic acids in Greek aromatic plants: Investigation of their antioxidant capacity and antimicrobial activity. Food Chemistry, 2006. 95(4): p. 664-671.

[16] Baublis, A.J., et al., Potential of wheat-based breakfast cereals as a source of dietary antioxidants. Journal of the American College of Nutrition, 2000. 19(sup3): p. 308S-311S.

[17] Kim, K.-H., et al., Phenolic acid profiles and antioxidant activities of wheat bran extracts and the effect of hydrolysis conditions. Food Chemistry, 2006. 95(3): p. 466-473.

[18] Yu, L., et al., Antioxidant properties of bran extracts from "Akron" wheat grown at different locations. Journal of Agricultural and Food Chemistry, 2003. 51(6): p. 1566-1570.

[19] Andreasen, M.F., et al., Intestinal release and uptake of phenolic antioxidant diferulic acids. Free radical biology and medicine, 2001. 31(3): p. 304-314.

[20] D Archivio, M., et al., Polyphenols, dietary sources and bioavailability. ANNALI-ISTITUTO SUPERIORE DI SANITA, 2007. 43(4): p. 348.

[21] Shahidi, F. and M. Naczk, Food phenolics: sources, chemistry, effects, applications. 1995: Technomic publishing company Lancaster.

[22] Velioglu, Y., et al., Antioxidant activity and total phenolics in selected fruits, vegetables, and grain products. Journal of Agricultural and Food Chemistry, 1998. 46(10): p. 4113-4117.

[23] McDonald, S., et al., Phenolic content and antioxidant activity of olive extracts. Food Chemistry, 2001. 73(1): p. 73-84.

[24] Rice-Evans, C.A., N.J. Miller, and G. Paganga, Structure-antioxidant activity relationships of flavonoids and phenolic acids. Free radical biology and medicine, 1996. 20(7): p. 933-956.

[25] Kandaswami, C. and E. Middleton Jr, Free radical scavenging and antioxidant activity of plant flavonoids, in 
Free radicals in diagnostic medicine. 1994, Springer. p. 351-376.

[26] Chang, C.-C., et al., Estimation of total flavonoid content in propolis by two complementary colorimetric methods. Journal of food and drug analysis, 2002. 10(3): p. 178-182.

[27] Amarowicz, R., Tannins: the new natural antioxidants? European Journal of Lipid Science and Technology, 2007. 109(6): p. 549-551.

[28] Bate-Smith, E. and T. Swain, Flavonoid compounds. Comparative biochemistry, 1962. 3: p. 705-809.

[29] Hagerman, A.E., Y. Zhao, and S. Johnson. Methods for determination of condensed and hydrolyzable tannins. in ACS symposium series. 1997. ACS Publications.

[30] Gülçin, İ., et al., Radical scavenging and antioxidant activity of tannic acid. Arabian Journal of Chemistry, 2010. 3(1): p. $43-53$.

[31] Isenburg, J.C., et al., Structural requirements for stabilization of vascular elastin by polyphenolic tannins. Biomaterials, 2006. 27(19): p. 3645-3651.

[32] Amarowicz, R., et al. Antioxidant activity of extracts of phenolic compounds from selected plant species. in Biologically-active phytochemicals in food: analysis, metabolism, bioavailability and function. Proceedings of the EUROFOODCHEM XI Meeting, Norwich, UK, 26-28 September 2001. 2001. Royal Society of Chemistry.

[33] Karamać, M., Chelation of Cu (II), Zn (II), and Fe (II) by tannin constituents of selected edible nuts. International Journal of Molecular Sciences, 2009. 10(12): p. 5485-5497.

[34] $\mathrm{Wu}, \mathrm{L}$., et al., Effects of tannic acid and its related compounds on food mutagens or hydrogen peroxide-induced DNA strands breaks in human lymphocytes. Mutation Research/Fundamental and Molecular Mechanisms of Mutagenesis, 2004. 556(1): p. 75-82.

[35] Atanassova, M. and V. Christova-Bagdassarian, Determination of tannins content by titrimetric method for comparison of different plant species. Journal of the University of Chemical Technology and Metallurgy, 2009. 44(4): p. 413-415.

[36] Hussin, M.H., Determination of total phenol, condensed tannin and flavonoid contents and antioxidant activity of Uncaria gambir extracts. Indonesian Journal of Pharmacy, 2013. 22(1).

[37] Huang, D., B. Ou, and R.L. Prior, The chemistry behind antioxidant capacity assays. Journal of Agricultural and Food Chemistry, 2005. 53(6): p. 1841-1856.

[38] Kratchanova, M., et al., Evaluation of antioxidant activity of medicinal plants containing polyphenol compounds. Comparison of two extraction systems. Acta Biochim Pol, 2010. 57(2): p. 229-234

[39] Ou, B., M. Hampsch-Woodill, and R.L. Prior, Development and validation of an improved oxygen radical absorbance capacity assay using fluorescein as the fluorescent probe. Journal of Agricultural and Food Chemistry, 2001. 49(10): p. 4619-4626.

[40] Č́ž, M., et al., Different methods for control and comparison of the antioxidant properties of vegetables. Food Control,
2010. 21(4): p. 518-523.

[41] Van der Rest, B., et al., Down-regulation of cinnamoyl-CoA reductase in tomato (Solanum lycopersicum L.) induces dramatic changes in soluble phenolic pools. Journal of experimental botany, 2006. 57(6): p. 1399-1411.

[42] Takeoka, G.R., et al., Processing effects on lycopene content and antioxidant activity of tomatoes. Journal of Agricultural and Food Chemistry, 2001. 49(8): p. 3713-3717.

[43] Núñez Sellés, A.J., et al., Isolation and quantitative analysis of phenolic antioxidants, free sugars, and polyols from mango (Mangifera indica L.) stem bark aqueous decoction used in Cuba as a nutritional supplement. Journal of Agricultural and Food Chemistry, 2002. 50(4): p. 762-766.

[44] Ferreira, P.M.P., et al., Moringa oleifera: Bioactive compounds and nutritional potential. Revista de Nutrição, 2008. 21(4): p. 431-437.

[45] Khalaf, N.A., et al., Antioxidant activity of some common plants. Turk. J. Biol, 2008. 32: p. 51-55.

[46] Sultana, B., F. Anwar, and R. Przybylski, Antioxidant activity of phenolic components present in barks of $<\mathrm{i}>$ Azadirachta indica $</ \mathrm{i}>,<$ i $>$ Terminalia arjuna $</ \mathrm{i}>,<\quad \mathrm{i}>$ Acacia nilotica $</ \mathrm{i}>$, and $<\mathrm{i}>$ Eugenia jambolana $</ \mathrm{i}>$ Lam. trees. Food Chemistry, 2007. 104(3): p. 1106-1114.

[47] Ozsoy, N., et al., $<\mathrm{i}>$ In vitro $</ \mathrm{i}>$ antioxidant activity of $<\mathrm{i}>$ Amaranthus lividus $</ \mathrm{i}>$ L. Food Chemistry, 2009. 116(4): p. 867-872.

[48] Ayoola, G.A., et al., Phytochemical screening and free radical scavenging activities of the fruits and leaves of Allanblackia floribunda Oliv (Guttiferae). International journal of health research, 2008. 1(2): p. 87-93.

[49] Céspedes, C.L., et al., Antioxidant and cardioprotective activities of phenolic extracts from fruits of Chilean blackberry $<\mathrm{i}>$ Aristotelia chilensis $</ \mathrm{i}>$ (Elaeocarpaceae), Maqui. Food Chemistry, 2008. 107(2): p. 820-829.

[50] Kumar, R.S., et al., Antimicrobial and antioxidant activities of Careya arborea Roxb. stem bark. Iranian Journal of Pharmacology \& Therapeutics (IJPT), 2006. 5(1): p. 35-41.

[51] Kaur, G., et al., Evaluation of antioxidant activity of $<\mathrm{i}>$ Cassia siamea $</ i>$ flowers. Journal of ethnopharmacology, 2006. 108(3): p. 340-348.

[52] Nsonde Ntandou, G., et al., Analgesic and anti-inflammatory effects of $<\mathrm{i}>$ Cassia siamea $</ \mathrm{i}>$ Lam. stem bark extracts. Journal of ethnopharmacology, 2010. 127(1): p. 108-111.

[53] Kumar, S., et al., Antioxidant and free radical scavenging potential of Citrullus colocynthis (L.) Schrad. methanolic fruit extract. 2008.

[54] Yildirim, A., M. Oktay, and V. Bilaloglu, The antioxidant activity of the leaves of Cydonia vulgaris. Turkish Journal of Medical Sciences, 2001. 31(1): p. 23-28.

[55] Fiorentino, A., et al., Spectroscopic identification and antioxidant activity of glucosylated carotenoid metabolites from Cydonia vulgaris fruits. Journal of Agricultural and Food chemistry, 2006. 54(25): p. 9592-9597.

[56] Pan, Y., et al., Antioxidant activity of microwave-assisted extract of longan $(<\mathrm{i}>$ Dimocarpus Longan $</ \mathrm{i}>$ Lour.) peel. Food Chemistry, 2008. 106(3): p. 1264-1270. 
[57] Soong, Y.-Y. and P.J. Barlow, Antioxidant activity and phenolic content of selected fruit seeds. Food Chemistry, 2004. 88(3): p. 411-417.

[58] Hung, T.M., et al., Antioxidant activity of caffeoyl quinic acid derivatives from the roots of $<\mathrm{i}>$ Dipsacus asper $</ \mathrm{i}>$ Wall. Journal of ethnopharmacology, 2006. 108(2): p. 188-192.

[59] Yen, G.-C. and D.-Y. Chuang, Antioxidant properties of water extracts from Cassia tora L. in relation to the degree of roasting. Journal of agricultural and food chemistry, 2000. 48(7): p. $2760-2765$.

[60] Auddy, B., et al., Screening of antioxidant activity of three Indian medicinal plants, traditionally used for the management of neurodegenerative diseases. Journal of Ethnopharmacology, 2003. 84(2): p. 131-138.

[61] Liu, X., et al., Identification of phenolics in the fruit of emblica $(<\mathrm{i}>$ Phyllanthus emblica $</ \mathrm{i}>$ L.) and their antioxidant activities. Food chemistry, 2008. 109(4): p. 909-915.

[62] Vayalil, P.K., Antioxidant and antimutagenic properties of aqueous extract of date fruit (Phoenix dactylifera L. Arecaceae). Journal of Agricultural and Food Chemistry, 2002. 50(3): p. 610-617.

[63] Saafi, E.B., et al., Phenolic content and antioxidant activity of four date palm (Phoenix dactylifera L.) fruit varieties grown in Tunisia. International Journal of Food Science \& Technology, 2009. 44(11): p. 2314-2319.

[64] Bagalkotkar, G., et al., Phytochemicals from Phyllanthus niruri Linn. and their pharmacological properties: a review.
Journal of pharmacy and pharmacology, 2006. 58(12): p. 1559-1570.

[65] Pilarski, R., et al., Antioxidant activity of ethanolic and aqueous extracts of $<\mathrm{i}>$ Uncaria tomentosa $</ \mathrm{i}>$ (Willd.) DC. Journal of ethnopharmacology, 2006. 104(1): p. 18-23.

[66] Wojdyło, A., J. Oszmiański, and R. Czemerys, Antioxidant activity and phenolic compounds in 32 selected herbs. Food Chemistry, 2007. 105(3): p. 940-949.

[67] Chainani-Wu, N., Safety and anti-inflammatory activity of curcumin: a component of tumeric (Curcuma longa). The Journal of Alternative \& Complementary Medicine, 2003. 9(1): p. 161-168.

[68] Zheng, W. and S.Y. Wang, Antioxidant activity and phenolic compounds in selected herbs. Journal of Agricultural and Food chemistry, 2001. 49(11): p. 5165-5170.

[69] Shahrbandy, K. and R. Hosseinzadeh, In vitro Antioxidant Activity of Polygonium hyrcanicum, Centaurea depressa, Sambucus ebutus, Mentha spicata and Phytolacca americana. Pakistan Journal of Biological Sciences, 2007. 10(4): p. 637-640.

[70] Yang, T., et al., A new antioxidant compound from Capparis spinosa. Pharmaceutical biology, 2010. 48(5): p. 589-594.

[71] Lee, K.-G. and T. Shibamoto, Antioxidant property of aroma extract isolated from clove buds $[<$ i $>$ Syzygium aromaticum $</ \mathrm{i}>(\mathrm{L}$.) Merr. et Perry]. Food Chemistry, 2001. 74(4): p. 443-448. 